\title{
La memoria crítica para una pedagogía dialógica en una cultura de la paz
}

Luis Alfonso Ramírez PeÑa*

\section{Aclaraciones y preliminares ${ }^{1}$}

Ni la guerra ni la violencia terminan con el solo acto de dejación de armas por parte de sus actores. Cuando cesan los conflictos, queda pendiente desarmar los espíritus y las mentes de quienes los han propiciado directa o indirectamente, pero también los de sus víctimas. Se requiere cambiar las representaciones tergiversadas de las causas y los contextos de la violencia, para encontrar espacios legítimos de convivencia y de respeto a las diferencias.

En el intento de conseguir interpretaciones y justificaciones, el tema de la violencia ha sido tratado desde diferentes aspectos, escenarios y perspectivas filosóficas y teóricas, pero en la mayoría de los casos enfocándose en la violencia física y poco en la violencia simbólica,

* Doctor en Educación, actual candidato a doctor en filosofía. Profesor del Doctorado en Educación de la Universidad Santo Tomás. Sus temas actuales de investigación están relacionados con la filosofía del lenguaje, el discurso pedagógico, la cultura clásica griega, la literatura latinoamericana y los estudios culturales.

1 Este capítulo es un informe inicial de la investigación Giro Pedagógico, que se viene adelantando con el apoyo del Fodeín (Fondo de Investigaciones) de la DUAD de la Universidad Santo Tomás. 
o en la causada por las agresiones verbales, actitudes de amenazas, insultos, desconocimientos, o incluso demostraciones de fuerza y de poder en contra del adversario. La preponderancia de los tratados concentrados en la violencia física ha llevado a varios investigadores a pensar que las soluciones definitivas a los comportamientos simbólicos de violencia desaparecen cuando se logra acabar con los hechos que los producían. El problema es descubrir las verdaderas causas. En el caso de la violencia en Colombia, lo complicado es determinar los orígenes, los causantes y las razones de las violencias campesinas en las luchas por la tierra, de las violencias políticas o ideológicas, las narcoparamilitares, etc. Y, como siempre, se corre el riesgo de visibilizar a unos y ocultar a otros, sin tener en cuenta las consecuencias que esto puede traer para el logro de una verdadera paz, y para encontrar salidas a los desastres económicos y los déficits de bienestar para la comunidad en general. Otro riesgo es que el fin de una guerra pueda crear nuevas fuerzas violentas que puedan revivir el conflicto armado en otros frentes.

Sin embargo, la historia muestra que antes y después de las guerras, los gestos de paz y de reconciliación emocional y simbólica que acompañan los actos de reparación de las víctimas, y que producen la verdad y olvido, son definitivos para el inicio o continuidad de culturas de paz. Uno de esos espacios simbólicos que permiten generar mayor influencia en crear condiciones definitivas de paz es la educación, y no solo la educación escolarizada e institucional sino todas las acciones pedagógicas que se pueden realizar desde los medios de comunicación masiva, las familias, las organizaciones sociales y las empresas. Se trata de un esfuerzo en conjunto para el colectivo social. El objetivo es lograr capacidad para recordar críticamente, y así recuperar la memoria colectiva que necesita replantearse. El reto es construir una cultura en la que todos puedan vivir, o convivir juntos, como diría Touraine (1996).

En el presente texto, se argumenta en favor de la tesis de que para propiciar una cultura de la paz es necesario revisar los discursos de la educación y de la pedagogía, con el fin de que sirvan al cambio de los imaginarios de violencia y las representaciones de sus actores. 
El propósito es que esos discursos influyan en el surgimiento de escenarios de convivencia y de respeto a las diferencias. Así, el objetivo de este capítulo es explicitar la justificación y las orientaciones para la creación de una cultura para la paz, centrados, principalmente, en las prácticas discursivas de la educación y la pedagogía. Proceso para el cual es indispensable crear nuevos medios de reconstruir memorias, dando usos diferentes a los testimonios para que repercutan en una práctica pedagógica dialógica en todos los espacios posibles. Para el desarrollo temático se incluyen algunas experiencias en la creación de culturas de paz, luego se exponen algunos factores que pueden obstaculizar estas nuevas culturas, el tratamiento de la memoria y contramemoria y, finalmente, el esbozo de un nuevo discurso pedagógico.

El presente capítulo surge de la necesidad de ejercer influencia en la creación de consciencia y de convicción acerca de la importancia de vivir en paz y, por lo tanto, de la urgencia de cambiar esta condición bélica que ha caracterizado la historia de Colombia. Debe agregarse que la creación de esta cultura es urgente porque persisten, aún después de los acuerdos, o de la dejación de armas, los mismos obstáculos para el logro de una paz duradera. Ejemplos: los modelos económicos, los intereses de grupos particulares de manejo del poder, y algunos prejuicios y odios surgidos más de la ignorancia que de factores materiales. Precisamente, esos son los factores que es necesario disminuir o liquidar, si es posible, como premisa necesaria en la búsqueda de la paz. La persistencia de aquellos obstáculos puede ocasionar grandes daños en la búsqueda de las renovaciones culturales requeridas y puede, en un momento dado, representar un peligro para la convivencia pacífica. Se trata de transiciones complicadas y tensionantes porque hay sectores ideológicos que siguen justificando la guerra, pero también porque en ella se ha creado una economía que se ve en riesgo de quedarse sin las fuentes de ingreso que la han sostenido. Por eso, el proceso es largo, tedioso y riesgoso, por lo cual se requiere a todos los sectores sociales amigos de la paz: las confesiones religiosas, los grupos y redes sociales, los gremios económicos, los medios de comunicación masiva y, muy particularmente, a los sectores intelectuales y de la educación. 


\section{Pedagogía para la paz}

Para superar el conflicto y establecer bases firmes que impidan la repetición de estos actos violentos, con la creación de una pedagogía para la paz es conveniente insistir en que el objetivo primordial es cambiar las representaciones y los imaginarios que las personas tienen de sí mismas y de sus relaciones con los demás en la constitución de las comunidades. Con estos cambios no se trata de proponer soluciones a los conflictos de violencia en las instituciones escolares o en sus entornos, causados en muchos de los casos por la pobreza y la desintegración familiar. Y aunque uno de los efectos que podría causar es el cambio de conductas violentas en los estudiantes, la propuesta busca, principalmente, lograr que cada individuo inmerso en una sociedad violenta cambie su visión del mundo. Esta propuesta se reduce a dos grandes procesos pedagógicos que pueden desarrollarse en forma simultánea: la reconstrucción crítica de la memoria histórica de la violencia, y el cambio del discurso pedagógico para hacerlo dialógico, en el sentido de darle voz crítica y responsable al estudiante.

La educación colombiana está llamada a desempeñar un papel central en la transformación definitiva de la cultura, para crear nuevas condiciones de vida y de relaciones en todos los habitantes del territorio nacional. Pero obviamente esta importancia de la educación en general plantea muchas inquietudes en relación con las normas que, actualmente, regulan y hacen funcionar la educación colombiana: ¿es posible crear espacios para una pedagogía para la paz?, ¿cómo puede la educación ser gestora básica en la creación de una cultura para la paz? Para brindar las respuestas se requiere partir del presupuesto de que tanto el Gobierno nacional como el local darían el respaldo efectivo y propiciarían el cambio necesario de la educación que facilite la creación de una cultura adecuada para nuevos escenarios de paz. Es el proceso natural porque

Un educador no puede ver la paz como el fin de la guerra, sino en un proceso de mediano y largo plazo que desactive las formas culturales de la violencia y construya procesos pedagógicos que 
nos enseñen a manejar los conflictos, sin ocultarlos, reconociendo en ellos la clave de nuestro crecimiento, haciendo de ellos el crisol del alma humana y permitiéndonos hacer una economía política de la agresividad. (Mejía, 1999, p. 37)

Introducir este componente de la paz en los currículos escolares de todos los niveles es atender a la necesidad de formación integral que tanto se menciona en los objetivos de las universidades, una educación integral que asuma como objetivo la formación, considerando a los estudiantes como individuos y personas, como ciudadanos y como profesionales, es decir, formar estudiantes que posean las condiciones para reconocerse, las actitudes y la voluntad de proponer y responder por sus comportamientos; con conocimientos y capacidades para problematizar el mundo y proponer respuestas; también, para ser ciudadanos responsables y participativos, propositivos en la búsqueda de una mejor organización social. Se trata de formar un profesional competente, con capacidad investigativa y de innovación que le aporte las mejores condiciones de vida a sus semejantes.

La creación de una cultura para la paz, desde nuestra perspectiva, es posible si se enfatiza y se aprovechan las potencialidades transformadoras del ser de los estudiantes, y su constitución como ciudadanos y profesionales, desde dos frentes o espacios que se pueden considerar integral y complementariamente: la memoria testimonial y el diálogo pedagógico.

\section{El caso de Alemania}

La historia violenta de Colombia no es comparable a las guerras acaecidas en cualquiera de las otras partes del mundo. Sin embargo, el parecido y el aprendizaje que se puede obtener de tales sucesos son aquellas acciones que siguen a la guerra y que pretenden crear un ambiente de paz, los cuales muestran la importancia de una cultura que supere las huellas que la guerra deja en las representaciones de los individuos.

Indudablemente, para pensar el acontecer de la violencia en Colombia (sus consecuencias, las propuestas sobre reparación, justicia 
y garantías de no repetición a sus víctimas) se justifica conocer las experiencias de otros pueblos, y la de Alemania es especial por sus consecuencias en el mundo moderno. No quiere decir que otros procesos de paz, como el de Sudáfrica, El Salvador, o el de Irlanda no tengan importancia, solo que el caso alemán es representativo porque se trata de uno de los países que hoy presenta una de las mejores economías de Europa, y porque ha tenido un movimiento intelectual bastante significativo, a pesar de los efectos de la guerra. Solamente se toman aquí algunos apartes del pensamiento de Adorno.

Adorno, consciente de lo que estaba pasando en su comunidad después del horror, ante la duda de qué hacer, afirmaba: "hoy la tarea más urgente de toda educación debe ser cifrada en la superación de la barbarie" (Adorno, 1998, p. 105). Muchos alemanes vivían una especie de responsabilidad propia por lo que había pasado: "En todo esto el discurso sobre el complejo de culpa tiene, sin embargo, algo de insincero. [...] el pasado terriblemente real pasa a ser convertido en algo anodino, en mera imaginación de los que se sienten por él afectados" (Adorno, 1998, p. 17). Es un recuerdo que se convierte en un lastre, en algo enfermizo y no propio del hombre práctico, quien no vive del pasado. Por el contrario, Adorno critica esta actitud y reclama, para todas las víctimas, dedicarles "lo único que nuestra impotencia puede regalarles, la memoria” (Adorno, 1998, p. 17). Y encontró en la educación el medio más apropiado para la liberación de las orientaciones de una educación antidemocrática.

Adorno propone al respecto una reflexión histórica. Rechaza la actitud de mantener una educación para acomodarse y no para transformar la propia cultura:

El valor de la posición asignada a la educación en relación con la realidad debería cambiar históricamente. [...] La educación en el hogar familiar, en la medida en que es consciente, en la escuela, en la universidad, debería tender, en este momento de conformismo omnipresente, antes a forzar la resistencia que a aumentar la adaptación. [...] La crítica de este realismo sobrevalorado me parece una de las tareas educativas más decisivas, que debería, 
en cualquier caso, ser acometida ya desde la primera infancia. (Adorno, 1998, p. 97)

Adorno, en ese momento de posguerra, creía en una educación que diera a los individuos su autonomía kantiana, la cual parte de la atribución de minoría de edad, en la que reconocen su culpabilidad por falta de valor mas no de entendimiento para superarla, alcanzando así la liberación. Así, minoría de edad es la incapacidad de "disponer de uno mismo, sin la dirección del otro". En consecuencia,

la democracia, descansa sobre la formación de la voluntad de cada individuo particular, tal como se sintetiza en la institución de la elección representativa. Para que de ello no resulte la sinrazón, hay que dar por supuestos el valor y la capacidad de cada uno de servirse de su entendimiento. (Adorno, 1998, p. 115)

Este proceso educativo no le corresponde a un solo nivel de la educación:

la tarea de procurar consciencia de la realidad, una tarea muy vinculada a la cuestión de la relación entre teoría y praxis no puede ser acometida, por así decirlo, al nivel universitario, sino que ha de serlo desde la formación infantil temprana y a lo largo de toda la vida mediante una genuina educación permanente. (Adorno, 1998, p. 98)

La combinación de teoría y práctica; de “atención a lo espontáneo y, a la vez, de concienciación, es algo así como la superación, precisamente, de la alienación” (Adorno, 1998, p. 99). La concienciación, entonces, es necesaria para que los individuos no se limiten a repetir procesos o aplicar fórmulas que no entienden, por el contrario, es concienciación para la formación crítica y propiciadora del cambio, no para repetir la historia como mero relato.

Becker, el interlocutor del texto que se está comentando, plantea la necesidad de exigir una "educación para resistir y para dominar las 
transformaciones”, que dé al individuo una dimensión completamente nueva, no estática (Adorno, 1998, p. 103). Y Adorno responde, sin embargo, "que la sociedad premia hoy a la no individuación, premia a los que hacen lo que todos hacen" (Adorno, 1998, p. 103). Pero Becker mantiene la convicción de que en la formación para comportarse en el mundo es necesario mantenerse en la relación dialéctica, un grado de adaptación al mundo para enfrentarlo pero conservando "sus cualidades personales" (Adorno, 1998, p. 96). Esta discusión sobre las contradicciones entre lo individual, lo social y lo objetivo en la educación se ha retomado actualmente en diferentes direcciones. Algunos hemos tomado la tarea de recuperar el rol de la persona o individuo sin negar la construcción y su formación como ser social y como conocedor de los mundos objetivos.

Esta era su voz de desconcierto por lo sucedido antes en Alemania. En Colombia la violencia fue, sigue y puede permanecer. La importancia de que los educandos conozcan lo que ha pasado en el país desde las diferentes voces puede servir para impedir la tergiversación de la verdad, para que formen su propio criterio y tengan suficiente consciencia de su realidad.

El llamado de Adorno está vigente y aplica a la situación violenta por la que ha transitado Colombia en particular, pero también para lo sucedido en el mundo: las cadenas sucesivas de guerras e invasiones por intereses culturales, religiosos y, lo más frecuente, por intereses geopolíticos y económicos. En contraste, la educación que se imparte es propia de un mundo y un país en supuesta armonía; solo se requiere gente preparada para que acuda a sus empleos que, supuestamente, los están esperando. Un panorama como el actual tiene gran importancia, pues exige espacios de reflexión en torno a la función de la educación, que no debe ser otra diferente a propiciar en los habitantes de Colombia el conocimiento crítico de su historia, para que se procuren sus propios proyectos de vida en función del país y de sus necesidades. Es el imperativo que se nos impone ante la realidad actual, donde la violencia física y simbólica ha marcado el destino de los habitantes y su territorio, ha dejado huella en cada uno de nosotros y ha fijado rutas de injusticia y de desesperanza difíciles de superar. 


\section{Alcance de las memorias narrativas ${ }^{2}$}

Precisamente, una de las preguntas que podemos estar haciéndonos en Colombia es: ¿cómo reparar a las víctimas de la violencia de cualquiera de los actores? Las respuestas estarán espontánea y naturalmente enfocadas en recuperar la memoria de las víctimas y la reparación de los males causados a sus familiares cercanos, quienes recibieron el impacto directo de estas tragedias. Sin embargo, poco se piensa en el país en su conjunto como víctima de la violencia generalizada que ha mantenido Colombia durante muchos años. De pensarlo, nos llevaría a preguntarnos en qué medida todos los habitantes somos culpables de la violencia, por acción u omisión. Así, si se acepta la responsabilidad del país nacional en los actos violentos, tendríamos que reconocer la doble condición de victimarios y víctimas. Como en toda cultura, los ejes de significación importantes se mueven en el sentido de que han sido creados con las cenizas de sus pasados, pero en algunos grupos sociales se han convertido en objeto de discusión para crear nuevos espacios de vida colectiva. Posiblemente, es lo que se tuvo que lograr con la cultura de posguerra en Alemania; la memoria que se recupera, pero convertida en un espacio en el que desaparecen los odios y las rivalidades entre las personas y los grupos, que se esfuerzan en vivir comunitariamente, en complementariedad, que se respetan, son solidarios en las adversidades y en la búsqueda permanente del bienestar colectivo.

Pero en Colombia, ante la realidad evidente de tener un país que no ha podido resolver este problema endémico de la violencia, las preguntas que surgen ahora, cuando supuestamente ha terminado el conflicto con uno de los frentes rebeldes, son: ¿qué puede hacer la sociedad en su conjunto para que se acabe la guerra definitivamente? ¿Qué medios utilizar para convencer a los enemigos de la paz de que participen en la creación de una cultura diferente? ¿Qué importancia puede tener la educación y la memoria colectiva en un programa de creación de una cultura de la convivencia pacífica? ¿Qué tratamiento

2 Como no se dispone del espacio ni del tiempo suficiente para una profundización, es recomendable el interesante trabajo de Gonzalo Sánchez (2011). 
dar a la memoria colectiva en sus diversas manifestaciones narrativas para crear un ambiente propicio y de exigencia de la paz? ¿Cómo mantener viva la memoria (en función reivindicadora y transformadora) de tal tradición para proyectar un nuevo país?

Obviamente, las respuestas varían según las explicaciones de las causas y de las responsabilidades asignadas. Podría afirmarse que la mejor reparación a las víctimas directas e indirectas de la violencia debe ser una justicia objetiva, transparente y efectiva. Pero con respecto al país, al conjunto de toda su población, para recuperar la memoria de las víctimas parece urgente que la educación colombiana transforme sus discursos, pero con una actitud crítica, situando responsabilidades y consecuencias, para conocer los orígenes como hechos históricos que no deben ser repetidos. Esta actitud crítica de la educación es necesaria para construir una Colombia donde sus gentes, conociendo las motivaciones y causas de la violencia, puedan tener esperanzas de un país mejor.

R. Sánchez (2011) enfatiza en la importancia de la memoria, pero con condiciones:

La memoria de los procesos sociales no se hace urgente por un simple afán de congelar el pasado, por una curiosidad de anticuario, sino por reconstruir el futuro. Si la memoria-anticuario se nos aparece como un sinsentido, porque vuelve reliquia el pasado, la memoria-proyectiva nos interpela porque se construye en función de un sentido, de un horizonte de futuro de la sociedad. (p. 76)

Es difícil entender que la narración de la memoria como repetición sea suficiente para labrar futuros u horizontes mejores para las víctimas y para el país ${ }^{3}$.

A partir de la discusión sobre la memoria y su reproducción narrativa, se argumenta aquí en favor de la tesis de que la educación es el

3 Son innumerables los trabajos acerca de la memoria, por ahora se puede recomendar la lectura de En busca del futuro perdido de Andreas Huyssen (2002) y, de Claude Calame, Prácticas poéticas de la memoria (2009). 
espacio adecuado para mantener la memoria de las víctimas, asumiendo colectivamente las responsabilidades y las posibilidades de reparación, en el sentido de comprender críticamente los orígenes de la historia violenta del país, de tal modo que se permita aplicar justicia, crear espacios de convivencia y mejores condiciones de vida para todos.

La memoria colectiva se revive por narrativas como las noticias, los testimonios de víctimas directas o indirectas, las narrativas literarias, por las historias y crónicas, por los juicios penales, etc. De estas, solamente los juicios penales son discutidos, y de tales debates judiciales se crean vencedores o vencidos. La literatura, ocasionalmente, puede provocar discusiones. Las demás narrativas se constituyen por relatos cuyo enfoque y valoración dependen de sus productores. Como toda narración, estos relatos asumen la condición de la interlocución; en otras palabras, al pertenecer a una producción del acto de comunicación, suponen un ámbito de relaciones con expectativas de información. Se espera obtener de ellos la mayor información posible de los hechos pero, por la mediación discursiva, el relato puede ser modulado a conveniencia del productor del discurso con el fin de impresionar a lectores o inducir a la audiencia en la dirección deseada. El interlocutor, a lo sumo, recibe el relato para conocer lo desconocido; sin embargo, según su presentación, el discurso puede satisfacer su expectativa sin que produzca efectos para superar el conflicto.

En los estrados judiciales se presentan testimonios, pero se someten a la confrontación de versiones, al hecho de que la construcción de una verdad judicial depende de los argumentos y contraargumentos de las partes, y a la ley con la cual se sanciona o se absuelve a los responsables. El efecto es quizás el ejemplo y la sanción social que impele a no repetir la falta, y la satisfacción psicológica y moral de los familiares de las víctimas, pero es una memoria que se diluye entre actos violentos y de diferente origen y razón, y va formando una especie de costumbre a la que todos se adaptan. Al respecto, Adorno (1998) afirma que "la realidad se ha vuelto tan prepotente que se impone a las personas, entonces nos encontraríamos con que hoy ese proceso de adaptación tiene lugar automáticamente" (p. 97).

La memoria acumulada de los medios de comunicación masiva está siempre presente y, aunque estos tienen la finalidad de informar, 
están subordinados a otras funciones e intereses como el de ser mejores en términos de espectacularidad (y hasta de morbosidad) y, naturalmente, de narrar desde la perspectiva ideológica que les conviene. Son innumerables los casos de la función no objetiva de los medios en la presentación de las noticias, no solo en el modo de hacerlo sino al seleccionarlas, en los énfasis y las fuentes consideradas ${ }^{4}$.

Los testimonios recogidos por investigadores, ONG, defensores de los derechos humanos o interesados, normalmente son invisibilizados y no tienen la circulación que merecen como para que repercutan en cambios contundentes en el conjunto de la sociedad.

La historia podría ser la narrativa más imparcial, pero no tiene el impacto requerido como para producir cambios definitivos en la actitud de los integrantes de los grupos sociales. La historia es memoria narrada y aunque están surgiendo historias en versiones críticas y de ensayo, el impacto es menor y reducido a las esferas académicas especializadas.

La literatura también podría considerarse como medio para reconstruir memorias críticas, pero al contener procesos de simbolización, su carácter de denuncia tiene unos efectos muy sutiles y bastante tardíos. Por ejemplo, una de las novelas actuales que se refieren a la violencia es la de Evelio Rosero, Los ejércitos, novela en la que se involucra en el conflicto al ejército oficial, a la guerrilla y a los paramilitares, y que transcurre en un pequeño pueblo colombiano. Aunque es una novela bastante leída y reconocida por la crítica internacional, en su condición crítica, es poco el impacto que tiene en la memoria colectiva. Este medio para mantener viva la memoria de las víctimas y el conocimiento de los hechos, aunque sea una visión profunda y crítica, no causa el efecto que se esperaría. Sin embargo, podría ser más efectivo, porque la lectura de una obra como Los ejércitos, a pesar de que es un relato

4 A propósito de la toma del Palacio de Justicia por el M-19, véase lo relacionado con el "pacto de silencio" que plantea Ana Carrigan en su libro El Palacio de Justicia, en 2007. Asimismo, puede leerse las recomendaciones que sobre los medios realizó la Comisión de Estudios sobre la Violencia, en 1988, publicadas en Colombia: Violencia y Democracia, por la Universidad Nacional de Colombia y Colciencias. 
descarnado, presentado a través de un maestro víctima y testigo, constituye un testimonio bastante aproximado a la realidad, en el que se muestran diferentes actores violentos con muy pocas diferencias en el uso de los medios para liquidar a su contendor.

Otro de los medios de fácil manejo en las aulas escolares son los testimonios presentados por investigadores sociales, entre otros, los de Alfredo Molano, que reflejan los hechos con un realismo crudo, pero valioso para convertirlos en textos de discusión en los adecuados espacios escolares. Su función efectiva no se cumple cuando se contempla o se sufre al conocer los detalles de lo relatado, sino cuando tales testimonios, al ser contextualizados en la realidad histórica de Colombia, sirven a una mejor comprensión crítica de las causas y de los factores que pudieron influir en tan tristes acontecimientos.

Los comentarios sobre estos intentos de mantener viva la memoria han fluctuado entre los críticos, que sostienen que no se deberían recordar aquellos hechos, y otros, que sostienen lo contrario con el fin de que no se repitan. Entonces, surge el interrogante acerca de cómo hay que actuar en la recuperación de la memoria para no repetir la historia, aparecen las preocupaciones iniciales para responder a la pregunta que Adorno se hacía después del Holocausto: ¿qué significa superar el pasado? De su mano, sabemos que

cuando se busca superar el pasado no se apunta a elaborar y asumir seriamente lo pasado, a romper su hechizo mediante la clara conciencia, sino que lo que se busca es trazar una raya final sobre él, llegando incluso a borrarlo, si cabe, del recuerdo mismo. (Adorno, 1998, p. 15)

Y afirma que quienes tienen esta pretensión de trazar una raya final sobre el pasado, llegando incluso a borrarlo, son los correligionarios de los culpables. Sin embargo, la idea del rechazo a olvidar el pasado amerita discusión, pues no se trata de olvidarlo para vivir doliéndose de lo que fue y se mantiene en la memoria actuante, en las decisiones y las opiniones de los individuos, se trata de mantener la memoria cuestionadora y transformadora positiva. 
La memoria es el contenido de las narrativas que se olvidan porque se sienten ajenas. Para valorar el papel de la memoria es necesario distinguir sus niveles de representación: imágenes y conceptos. La memoria en imágenes circula hoy con frecuencia, dejando huellas inadvertidas en cada uno de los interlocutores. Con esta, se recuerda el acto en su totalidad concreta, como los recuerdos de los hechos de la toma del Palacio de Justicia, desde su inicio hasta el desencadenamiento final, tal como lo vimos y nos lo contaron los medios de comunicación masiva. Son los recuerdos de las imágenes percibidas directamente de la televisión, o como alguien nos las contó, incluso en la escuela donde, como apunta Ortega (2002), pueden existir limitaciones:

es el hecho de cómo el discurso que ofrece la escuela, a pesar de la creciente y progresiva introducción de tecnología educativa como recurso y estrategia de aula, es un discurso eminentemente centrado en la palabra y cómo la mayor parte de los intereses de los jóvenes vienen configurados básicamente en la cultura de imágenes de su vida cotidiana. (p. 33)

Las imágenes, como elemento mediador de la información, se han impuesto en toda la cultura mediatizadora contemporánea sustituyendo la palabra, reduciendo así la información a la pura percepción, al impacto de la imagen. Ese es el medio con el cual se informa sobre todo, incluso sobre las guerras y los actos violentos del mundo, sin dejar espacio para la reflexión y la crítica. Y esta manera de ver y representarse el mundo constituye la misma ideología. Adorno (1998) lo expresaba de otra manera:

La organización del mundo en que vivimos y la ideología dominante - de la que apenas cabe decir ya que sea una determinada cosmovisión o una teoría-, son hoy, en primer lugar, lo mismo; la organización del mundo se ha convertido ella misma de modo inmediato en su propia ideología. (p. 96) 
Ideología que se hace patente en las palabras, en los discursos de la inmediatez, de las representaciones concretas sin espacio para las dudas. El encuentro con los relatos de nuestra propia realidad y condición, de nuestro grupo social, es percibido, si acaso, como un contacto que no interesa ni mantener en la memoria, y menos, que incite a interrogarse por causas o circunstancias. Razón por la cual, ante la reiteración permanente en los medios masivos de comunicación de ciertos enfoques estereotipados que llaman noticias, estos se memorizan, se repiten y hasta se justifican sin haberlos entendido, y menos verificado.

Y la memoria colectiva que domina al conjunto de circunstancias y acciones, de la que no se hace ningún ejercicio de interpretación, es una ideología que constituye el criterio de validez para todo, hasta para menospreciar el pasado:

La memoria, individual o colectiva, se exalta "como algo más auténtico, espiritual y poderoso que la historia, que se condena como una 'memoria muerta". Supone, además Historia y Memoria una hermenéutica especial, porque en vez de privilegiar los lugares de la tradición recibida, como hace la hermenéutica clásica, pone el acento ahora en los momentos despreciados o declarados insignificantes". (Sandoval, 2016, p. 211)

Pero la historia, que tiene esa posibilidad de resaltar lo olvidado, puede ser memoria tergiversada, que oculta la verdad por intereses de diferente orden. Una historia plana de los hechos, que no tenga espacio para la crítica, siempre deja muchas dudas.

Por otro lado, la recuperación de la memoria debe hacerse en el marco de la defensa de los derechos humanos, y nada más apropiado para ello que la educación: "Se propone que la elaboración de la memoria para una cultura y una educación por la paz, tenga sus cimientos en los derechos humanos, en los derechos colectivos, y en las dinámicas, pensares y haceres organizados desde la paz y por la paz" (Sandoval, 216, p. 211). 
En consecuencia, ante una nueva alternativa de construcción de sujetos y de subjetivaciones, en cualquier revisión crítica del pasado es urgente que se tematicen las realidades violentas sucedidas, que sean discutidas e incorporadas en el discurso pedagógico con estructuras polémicas o argumentativas. Estamos en una época en que el sujeto recupera su presencia a través de su voz. El sujeto que en la modernidad había sido reconocido en una voz unánime y universal, esencial en la historia, comienza a ser reconocido en su voz particular. Como dice G. Sánchez (2011):

Estamos en una ebullición de la palabra. Las organizaciones de derechos humanos, de víctimas, las regiones, y también los perpetradores, hablan y hablan... Y es mucho lo que está por contarse. Variados sectores de la sociedad y de la política permanecen aún en calculado silencio. (pp. 71-72)

Estos son justos reclamos: oír a quienes de alguna manera han sido víctimas o victimarios. Pero la pregunta, el interrogante permanente es ¿qué hacer con estos testimonios?, y a partir de mi experiencia en teorías del discurso, también interrogo: ¿la condición narrativa de estas memorias no es susceptible de olvido, no deja al colectivo social con las mismas huellas históricas, sin posibilidad de superarlas? No son acontecimientos de los que se debe contar solamente el recuerdo del asalto, el asesinato de manera cruel a campesinos que por alguna razón o interés han sido señalados; es una memoria que debe relatar lo sucedido, incluyendo la razón histórica que ha asesinado a tanta gente en el país. Sánchez (2011) lo aclara:

La memoria que nos interpela no es una memoria de objetos, es la memoria de una violencia que tiene como objeto "aniquilar a los hombres y la memoria de los hombres". Es una memoria de acontecimientos, de relaciones, y no de objetos. En un siglo de demoliciones, de ocultamiento de las ruinas y las huellas, la memoria surge como un aparato de reconstrucción: 
demolición-reconstrucción es como podría definirse el campo de lucha por la memoria. (p. 78)

Los testimonios auténticos contribuyen al conocimiento de las diferentes facetas de la realidad violenta; son útiles para desmitificar narraciones que han atribuido a un determinado sector toda la responsabilidad, con lo cual invisibilizan otras responsabilidades. Por ello es necesario conocer la verdad, aunque sea indiscreta, y que sea contada por las víctimas, pero también con otros usos de la palabra y el lenguaje:

Desde luego, hemos tomado conciencia de la fuerza de la palabra, pero también del impacto simbólico de los gestos y de sus antípodas: la hoja en blanco, la silla vacía, el minuto de silencio, la boca vendada, la marcha del silencio, son todos elementos de ese acervo comunicativo. (Sánchez, 2011, p. 71)

¿Por qué es urgente apelar a la memoria? La memoria de la violencia en Colombia es indispensable porque amplios sectores de la población colombiana la desconocen, con el efecto de que, fácilmente, ante el influjo de intereses políticos o religiosos, se crean prejuicios sobre las soluciones posibles. Este desconocimiento ha conducido a muchos sectores sociales a ser insolidarios con los habitantes de amplias regiones de la geografía colombiana que tras el acuerdo de paz recibirían el mayor beneficio inmediato, la restitución de sus tierras, el cese del fuego cruzado, de los desplazamientos, etc. Se ha perdido hasta la capacidad para entender que con los acuerdos de paz todos somos beneficiarios: los comerciantes y empresarios, los desempleados... Parte de este desconocimiento se debe a los modos de recibir la información, pero más allá de que los medios informan creando prevenciones y rechazo a la noticia, "A la luz del conflicto armado en Colombia y asumiendo que pese a él se está hablando, cabría preguntarse: ¿está la sociedad en condiciones de escuchar? ¿O están las víctimas en un monólogo revictimizante? Es una pregunta inquietante para todos" (Sánchez, 2011, p. 73). Estas dudas sobre cómo lograr que se conozca la verdad son, entre 
otras, las razones para proponer un proceso a largo plazo, teniendo la educación como el medio más apropiado para hacerlo.

\section{Una educación para la paz}

La educación para la paz requiere hacer cambios significativos en las concepciones y modos de la docencia, y poner el diálogo como el centro de la relación entre docentes y estudiantes. Una relación que no sea la de dar y reproducir, sino de construir saberes y haceres de los mundos subjetivos, intersubjetivos y objetivos. Serían actos de interacción comunicativa en los que surgen, de cada uno de los participantes, preguntas y respuestas que a la vez generan otras. Los estudiantes y profesores no se basan en la repetición sino en problematizar, en dudar; con esto cada uno de ellos se va constituyendo como el origen y responsable de sus puntos de vista, porque los sustenta y los practica con coherencia.

Una propuesta de diálogo pedagógico como la anterior, cuyos referentes importantes sean la memoria histórica y sus resultados actuales, puede servir para despejar dudas (incluso inconscientes), superar resentimientos, odios, injustos, o hasta perdonar y olvidar, cuando se conoce la verdad y sus circunstancias.

A este respecto, tienen pertinencia las propuestas de la pedagogía crítica que han mostrado interés por una educación que ponga en el centro de atención las actuaciones de los estudiantes en la vida, no para la vida. Un enfoque pedagógico a la manera de la pedagogía crítica puede presentar orientaciones básicas para una educación que supere la narrativa de las memorias parcializadas, recordadas desde un solo punto de vista, para, en las alternativas posibles, presentar y discutir sus diferentes versiones. Paulo Freire, con la "pedagogía del diálogo", y H. Giroux con la "pedagogía de los límites”, ofrecen pautas no solo para poner en discusión las diferentes voces que constituyen los discursos de la violencia y su cultura en Colombia, sino también para pensar una educación más comprometida con la realidad nacional y su transformación. 
La pedagogía del diálogo de Paulo Freire es una alternativa para educar a partir de la propia realidad de los estudiantes, asumiendo responsabilidades de transformación consigo mismo y con el entorno. Acertadamente, Freire (1993) critica esa educación en la que

en lugar de comunicarse, el educador hace comunicados y depósitos que los educandos, meras incidencias u objetos, reciben pacientemente, memorizan y repiten. He aquí la concepción bancaria de la educación, en la que el único margen de acción que se ofrece a los educandos es el de percibir los depósitos, guardarlos y archivarlos. (p. 65)

Propone a cambio una educación dialógica en la que

el diálogo es una exigencia existencial. Y si él es el encuentro en que se solidariza el reflexionar y el obrar de sus objetos dirigidos al mundo para transformarlo y humanizarlo, no puede reducirse a un acto de depositar ideas de un sujeto en el otro, ni tampoco volverse simple cambio de ideas que deben ser consumidas por los permutantes. (Freire, 1993, p. 98)

El mundo para transformar y humanizar que refiere Freire es precisamente nuestra propia historia violenta y nuestra realidad. De donde surge la esperanza de poner este mundo al servicio de la convivencia y de mejores condiciones de vida para todos.

Por su parte, H. Giroux (2003a) propone otra pedagogía crítica: "La pedagogía de los límites brinda a los alumnos una oportunidad de poner en juego las numerosas referencias que constituyen diferentes códigos culturales, experiencias y lenguajes" (p. 210). Así, esto implica crear condiciones para que los estudiantes lean los diferentes códigos, incluso las voces propias, y les encuentren sus límites. Al diferenciar códigos se reconoce también la parcialidad y la autoridad que puedan tener las voces en una visión transgresora, con lo cual 
"los alumnos atraviesan fronteras de significados, mapas de conocimientos, relaciones sociales y valores que se negocian y reescriben cada vez más, a medida que se desestabilizan y reconfiguran los códigos y las regulaciones que los organizan" (Giroux, 2003a, p. 210). De esta manera el aprendizaje queda estrechamente vinculado a los “cambiantes parámetros de lugar, identidad, historia y poder" que, en el caso colombiano, se refieren a la historia conflictiva y desigual de sus actores. En el desarrollo curricular se incorporan los diversos textos y versiones, no solo los oficiales o los paradigmas tradicionales, en variedad de formas de expresión escrita, oral y audiovisual. De igual manera, se amplían los modos de hacer lecturas; no reducidas a la comprensión de los contenidos objetivos textuales, sino abiertas al análisis de las diferentes voces y sus relaciones y, por otro lado, a la profundización en la crítica con el uso de las voces propias del lector (Scholes, 1985).

Otro aspecto importante de las prácticas discursivas en una pedagogía de los límites es el cambio del modo de presentar los saberes como contenidos unificados y con una pretensión de verdad, de discurso único. La lectura analítica y crítica, mencionada antes, implica asumir las memorias, los saberes de la historia no como únicos, sino reconociendo otras voces, ninguna como definitivamente verdadera:

Es imperativo que los educadores críticos desarrollen el discurso de la contramemoria no como narrativa esencialista y cerrada, sino como parte de un proyecto utópico que reconozca "el carácter compuesto, heterogéneo, abierto y en última instancia, indeterminado de la tradición democrática”. (Giroux, 2003a, p. 217)

Tradicionalmente se han presentado los hechos en una versión oficial y unificada, desde un solo historiador, mientras que "la cuestión pedagógica es enunciar la diferencia como parte de la construcción de un nuevo tipo, que sea a la vez múltiple y democrático" (Giroux, 2003a, p. 217). 
Giroux (2003a) cita a Foucault, para quien la contramemoria es una práctica que

transforma la historia, que deja de ser un juicio sobre el pasado en nombre de la verdad presente para convertirse en una "contramemoria" que combate nuestras modalidades actuales de verdad y justicia, y nos ayuda a entender y cambiar el presente poniéndolo en una nueva relación con el pasado. (p. 217)

La contramemoria resulta equivalente a la "rememorización", y no se puede confundir con la costumbre, que es vista por Giroux, retomando a Smith, como si construyera sujetos dentro de un discurso de la continuidad, en el que el conocimiento y la práctica se consideran un tema de herencia y transmisión. La costumbre es el complejo de ideologías y prácticas sociales que ve la contramemoria como subversiva, y la enseñanza crítica como antipatriótica:

La rememorización es parte de un lenguaje de la vida pública que promueve un diálogo entre pasado, presente y futuro. Es una visión optimista enraizada en la necesidad de prestar testimonio ante la historia, recuperar lo que no debe ser olvidado. Es una visión de la vida pública que demanda una interrogación permanente del pasado, que permita a los diferentes grupos situarse en la historia, al mismo tiempo que luchan por hacerla. (Giroux, 2003a, p. 220)

La educación debe asumir el compromiso de generar los cambios en las subjetividades, individual y colectivamente, comprendiendo las diferentes causas de la violencia y las fuerzas que la mantienen; una educación que no consista en ponerse de acuerdo o en establecer consensos que cierren el discurso y terminen imponiéndose a los demás. La educación, más que un espacio para aprender lecciones, es espacio de debate, para escuchar las diferentes versiones y controvertir con argumentos. Así, el estudiante, más que lograr el aprendizaje de datos 
o informaciones, se acerca a los diversos modos de conocer y de buscar verdades.

El diálogo que se propone para el ejercicio pedagógico en las instituciones y en los demás ámbitos de la vida social, se despliega en interacciones de voces, sin límites. Es un proceso que exige estructuras discursivas argumentativas, en oposición a las estructuras narrativas que enfatizan el recuerdo frío de los acontecimientos. Además, debe privilegiar las prácticas de conocimiento hermenéutico, que mantengan abierta la posibilidad de acceder a las interpretaciones de los mundos referidos.

En este sentido, la reparación a las víctimas, y al conjunto del país, se lograría con esa educación que rememoriza críticamente los acontecimientos de violencia, pero al mismo tiempo crea la posibilidad de perspectivas de futuro, de esperanzas de una vida mejor con justicia y equidad, lo que deberá convertirse en la razón de lucha de cada uno para conseguir la reparación completa. Para ello, es necesario cambiar los modelos pedagógicos unidireccionales y monológicos hacia una actitud dialógica que convierta al estudiante en actor de su propia formación, para que comience a ejercer su autonomía y libertad con responsabilidad social, siendo agente consciente de lo que quiere y de lo que busca para el bien de sí mismo y de los demás.

Una pedagogía para crear cultura de la paz solamente es posible cuando los actores cambian su percepción del otro, cuando abandonan su actitud personalista e individualista hacia los demás, e incluso hacia sí mismos. Se cambia cuando se valora al otro en su propia diferencia, reconociendo en él a un ser que tiene virtudes personales sin que necesariamente sean iguales a las de los demás. Estas actitudes de respeto y consideración hacia los demás deben ser el resultado de la propia y permanente evaluación y valoración de las acciones para que, cuando se viva en comunidad, en lugar de juzgar y condenar a los demás por sus malos actos, se examinen las causas y hasta las mismas responsabilidades que se pueda tener en ellos. Se tiende a condenar a los demás antes que examinar las posibles responsabilidades de sí mismo. Precisamente, el egoísmo es el afán desaforado de buscar en todas las acciones individuales y colectivas los mayores réditos, sin importar los 
medios y las consecuencias, el enriquecimiento ilícito, la corrupción, la apropiación de bienes y recursos públicos... El dogmatismo es otro de los males de nuestra época: cuando no se aceptan ni se dan razones al escuchar o emitir opiniones, cuando se emiten juicios ligeros y muchas veces irresponsables, no se mide las consecuencias que estos puedan tener en los demás.

El resultado de esta educación no puede ser la unificación cultural, por el contrario, tendrá que reconocerse la multiculturalidad y la diversidad de voces:

Como hipótesis central que en el entrecruce de todas las reflexiones políticas, sociales, económicas sobre la violencia y la guerra existe un peligro al olvidar los énfasis culturales y educativos de esa problemática, intentando hacer una primera aproximación a la búsqueda desde la multiculturalidad crítica y el conflicto. (Mejía, 1999, p. 33)

Resulta entonces todo lo contrario a mantener la unificación. Se trata de "hacer un análisis de la globalización capitalista de estos tiempos, sus esfuerzos por conseguir una homogeneización y la manera como la diferencia y la desigualdad arrebatan un mundo hegemónico desde las nuevas formas del poder" (Mejía, 1999, p. 34).

Lograr una cultura en la cual se reconozca al otro implica

Comenzar por reconocer la diferencia, significa la capacidad de construir una relación entre mi mundo de sentidos y de acciones y desde mi identidad, de establecer lo otro que no es como lo mío. Esto va a permitir construir de otra manera mi relación social, en cuanto allí voy a poder producir "mi versión" [...], el lugar desde el cual yo, con mi huella, produzco mi texto, surgido desde mi praxis, me abro a la búsqueda de la intertextualidad (de instituciones, personas, grupos humanos), rompiendo en mí la estructura de poder que no deja emerger lo diferente. (Mejía, 1999, pp. 38-39) 
Allí tiene lugar el origen de los enunciados: son las personas quienes, desde sus propias experiencias, establecen relaciones e incluyen otros textos para la configuración de uno nuevo.

Sin embargo, la idea de que el sujeto produce desde su experiencia el reconocimiento de lo otro, (Mejía, 1999, p. 39) es incompleta, pues el reconocimiento de lo otro se hace en un reconocimiento del otro, es decir, de quien hace posible la interlocución para el reconocimiento.

Por lo tanto, la construcción del individuo como diferente, se va dando por las múltiples relaciones con los demás, con su comunidad, sin dejarse reducir a la condición de los otros. Así, la afirmación de que "Nos situamos frente a una construcción de lo colectivo desde múltiples lugares, pero que ubicando la diferencia como elemento central me constituye como ser social con responsabilidades colectivas y que son necesarias de re-construirse." (Mejía, 1999, pp. 38-39), no puede entenderse en el sentido de que tal socialización se da para reducir la diferencia: yo soy para mí, para los otros, y para lo otro; eso es lo que me permite convivir.

No hay dudas de que, para conseguir una cultura de la paz, es necesario transformar la educación. Solamente a partir de una educación para la paz en actitudes de diálogo pedagógico puede construirse una cultura para la paz.

\section{Posibles dificultades para el desarrollo de una pedagogía para la paz}

Para emprender programas y estrategias para la creación de ambientes de paz se requiere vencer, antes y durante el proceso, varios obstáculos que necesariamente surgen en el desarrollo normal de estas propuestas. Uno de los grandes obstáculos con los que cuenta cualquier intento de reforma de la educación colombiana y mundial es el imperativo de la globalización que, a juzgar por sus exigencias, persigue resultados diferentes a los requeridos para una educación para la paz. La globalización exige formar personas con habilidades para competir. La OCDE (Organización para la Cooperación y 
el Desarrollo Económico) define esa orientación de la globalización, así: "La Globalización y la modernización están creando un mundo incrementalmente interconectado y diverso. Para darle buen sentido y función en este mundo, los individuos necesitan, por ejemplo, dominar las cambiantes tecnologías y darles sentido a grandes cantidades de información disponible" (OCDE, 2005, p. 4). Se trata de dotar a los educandos con capacidades individuales que les permitan participar más activamente y con eficiencia en los procesos de la globalización. Así, las competencias básicas están orientadas al manejo de nuevos lenguajes y tecnologías de la información, a la formación de autonomías capaces de aprender sin profesor, y al fortalecimiento de la internacionalización de los grupos y redes con las prácticas, pasantías e intercambios de estudiantes.

Las tres exigencias anteriores de la OCDE como parte de la integración de una educación de calidad se han venido cumpliendo con mucho esmero en las universidades, tanto en educación possecundaria como en la educación posgradual. Más que en cualquier otro aspecto de la formación integral de los estudiantes, se insiste en la internacionalización con intercambios de estudiantes y profesores, dobles titulaciones, etc., en la organización de la actividad académica curricular por créditos, enfatizando en la indagación y el estudio fuera del aula y, en algunas universidades, en la utilización de la metodología АBP (aprendizaje basado en problemas). Quizás lo más generalizado sea la inmersión completa en las TIC, particularmente en todas las herramientas pedagógicas disponibles.

Esta tendencia en la educación está confirmada en el programa y el plan de desarrollo del presidente Juan Manuel Santos, que no presentaba ningún contenido que se identificara con la intención de orientar la educación para construir la paz. Más bien, pareciera que los acuerdos de paz tuvieran la intención de crear mayor seguridad para una mayor inversión, para mayor productividad y para facilitar el desarrollo de empresas nacionales, o la expansión de empresas del sector energético en los campos de producción minera y petrolera. Consecuente con ello, se puede observar en las nuevas regulaciones sobre la educación, y especialmente sobre la educación superior, que están orientadas más a asegurar una educación basada en competencias que garanticen un buen 
hacer, antes que un excelente ser. La calidad de la educación se traduce en la capacidad de producir, con los mejores estándares de eficiencia, resultados en todos los sectores de la economía nacional, con el fin de competir de la mejor manera. Se sigue, así, actuando y contribuyendo a la cultura de la globalización, cuyos objetivos pueden obstaculizar la creación de una mentalidad propicia para la paz. Se busca, en la actual regulación oficial de la educación, orientar los procesos pedagógicos hacia la formación de individuos productivos, competitivos, eficientes, y que puedan insertarse en el sector productivo en condiciones de lograr buenos resultados. La formación integral se reduce a relacionar teoría y práctica, pero trata muy poco sobre la integración social o la formación de la persona como ser pensante y de deseos.

Por lo anterior, proponer un plan para una cultura de la paz implica cambios en la regulación oficial de las prácticas pedagógicas en todos los niveles de la escolaridad pero, como se expone en otro trabajo sobre la globalización y la educación (Ramírez, 2016), no parece haberse emprendido algún cambio, ni curricular ni pedagógico, para esta nueva cultura (Ramírez, 2016).

Con el cambio de regulación, que no se ha emprendido, se respondería a quienes prefieren mantenerse en una cultura de productividad: "Los defensores de la cultura empresarial ya no consideran la educación pública en relación con su función cívica, sino, sobre todo, como operación comercial en la que el consumismo es la única forma de ciudadanía que se ofrece a los jóvenes" (Giroux, 2003b, pp. 84-85). Con esta convicción, Giroux sostiene además que "la reducción de la educación pública a los imperativos ideológicos del orden empresarial va en contra de las demandas sociales críticas de educar a ciudadanos para que sostengan y desarrollen unas identidades, relaciones y esferas públicas democráticas inclusivas." (Giroux, 2003b, pp. 84 y 85). En Colombia, esta cultura empresarial se acompaña de una cultura política empañada por la corrupción y los intereses individualistas, alejada de cualquier compromiso real con la transformación del país en un vividero en paz y con la superación de las injusticias sociales.

Se ha insistido, en este texto, en el contraste que hay entre una formación de personas comprometidas con su realidad social y su propia 
responsabilidad de ser, y aquella para acomodarse y asumir todo aquello que estandariza y liquida las diferencias. Esta formación que atenta contra la diferencia y en la que se enmarca la educación en el mundo globalizado tiene, según Mejía:

[la] pretensión de construir una cultura global unificada y, por tanto, producir subjetividades e identidades más o menos homogéneas que tendrían como realidad una especie de pre-formatividad (a priori) de la acción y de la historia, produciendo una homogeneización que oculta experiencias de vida y experiencias sociales extremadamente diferentes, además del profundo desfase que ha mostrado entre economía y ética y moral. (Mejía, 1999, p. 40)

También, Touraine plantea, respecto a la nueva concepción del educando, que es como si se estuviera formando a un trabajador:

Cuando el individuo deja de definirse en principio como miembro o ciudadano de una sociedad política, cuando se lo percibe, en primer lugar, en cuanto trabajador, la educación pierde su importancia, porque debe subordinarse a la actividad productiva y el desarrollo de la ciencia, la técnica y el bienestar. (Touraine, 1996, p. 274)

Apunta precisamente a la tendencia actual de la educación a formar trabajadores, mano de obra, para lo cual se requiere formar en competencias que, aunque se diga que son para el hacer y el ser, enfatizan el desempeño eficiente.

La presentación de los anteriores puntos de vista deja entrever un conjunto de intereses que podrían no ser compatibles con los fines de una educación para la paz. Desde luego, el Estado colombiano se enfrenta al dilema de cumplir con las exigencias de la OCDE que, como ya lo mencionamos anteriormente, privilegia la educación para el hacer o, por el contrario, impulsar la educación para constituir el ser, con la cual se podría promover la educación para la paz. Es posible que se pueda pensar una alternativa intermedia que acoja los imperativos 
de la globalización y, al mismo tiempo, forme personas, ciudadanos y profesionales críticos que se apropien de los medios y los métodos para mantenerse en búsqueda de la verdad.

Para concluir aquí esta reflexión, estas ideas sueltas de una propuesta para la formación de una cultura de la paz, no dudo en reiterar la urgencia de emprender un nuevo tratamiento crítico de la memoria colectiva, de la historia violenta de Colombia (reconociendo que esta hace parte de nuestra cultura) y de aprovechar todos los escenarios posibles, con mayor énfasis en la educación de todos los niveles, manifestaciones y medios, para convertir a cada uno de los educandos en gestores de paz, de tal modo que puedan vivir en tranquilidad y solidaridad con los demás.

\section{Referencias bibliográficas}

Adorno, T. (1998). Educación para la emancipación. Madrid: Morata.

Calame, C. (2009). Prácticas poéticas de la memoria. México: Universidad Autónoma Metropolitana y Siglo xxI.

Carrigan, A. (2009). El palacio de justicia. Tragedia colombiana. Bogotá: Ícono

Comisión de estudios sobre la violencia (1988). Colombia: Violencia y democracia. Bogotá: Universidad Nacional de Colombia, Colciencias.

Freire, P. (1993). Pedagogía del oprimido. México: Siglo XxI

Giroux, H. (2003a). Pedagogía y Práctica de la Esperanza. Buenos Aires: Amorrortu.

Giroux, H. (2003b). La inocencia robada. Juventud, multinacionales y politica cultural. Madrid: Morata.

Huyssen, A. (2002). En busca del futuro perdido. México: Fondo de Cultura Económica.

Mejía, M. R. (1999). "En busca de una cultura para la paz. Desde una pedagogía del conflicto y la negociación cultural (documento en construcción)". En A. Mockus, Educación para la paz. Una pedagogía para consolidar la democracia social y participativa (pp. 33, 37, 38, 39, 40). Bogotá: Magisterio. 
Organización para la Cooperación y el Desarrollo Económico [OCDE] (2005). The definition and selection of key competences. Executive summary. Recuperado de www.ocde/edu/statistics/deseco

Ortega, J. E. (2002). Memoria, hermenéutica y educación. Madrid: Biblioteca Nueva

Ramírez, L. (2016). Intertextos de la globalización en el discurso de la educación colombiana de Juan Manuel Santos. En G. Olave y E. Arnoux (coords.). Discurso y Política en Colombia: problemáticas actuales. Medellín: La Carreta.

Sánchez, G. (2011). La desmemoria de los victimarios. Silencios y voces de víctimas y victimarios. Anthropos, (230), 71-79.

Sandoval, A. E. (2016). Educación para la paz integral. Memoria, interculturalidad y decolonialidad. Bogotá D. C.: Arfo.

Scholes, R. (1985). Textual Power. United States: Yale University Press.

Touraine, A. (1996). ¿Podremos vivir juntos? La discusión pendiente: el destino del hombre en la aldea global. Buenos Aires: Fondo de Cultura Económica.

Verón, O. (2011). Memoria, violencia y progreso: rostros ocultos de un país. Anthropos, (230), 57-70. 
